DOI: 10.20472/IAC.2020.056.009

KEREN MICHAEL

The Max Stern Yezreel Valley Academic College, Israel

GALIT YANAY-VENTURA

The Max Stern Yezreel Valley Academic College, Israel

\title{
EMPLOYEES' PERCEPTIONS OF MANAGEMENT STYLE AND PATTERNS OF DECISION-MAKING AS CONTRIBUTING TO ORGANIZATIONAL COMMITMENT
}

\begin{abstract}
:
Different management styles obtain various organizational environments and diverse emotions among employees. Establishing a cooperative environment in the work place is one of the main tasks of managers in organizations today, which contribute to satisfaction and organizational commitment. High levels of organizational commitment diminish tardiness and absenteeism on one hand, and enhance performance and organizational efficiency of employees on the other hand.

Aims: The study aims were twofold: 1) to examine how perceptions of employees about management styles and patterns of decision-making contribute to organizational commitment. 2) to examine the differences in the senses of organizational commitment between employee groups according to several organizational characteristics.

Method: The sample included 300 service organizations' employees (43.3\% men) aged $19-73$ (Mage $=31.5$ ). All employees completed self-reported questionnaires measuring management style, shared decision-making, and organizational commitment.

Results: A path analysis, based on multiple regressions, demonstrated that emotional commitment was predicted by employees' perceptions that there is a pattern of shared decision-making in the organization and that their supervisors use social management style. Similarly, pattern of shared decision-making was predicted by using social management style. In addition, higher levels of emotional commitment exist among men, older employees, full time employees, employees that hold a seniority status in the organization, and employees who are married with children.

Conclusions and Implications: According to the results, managers should make efforts in fostering interpersonal relations and senses of cooperation, so that employees can be emotionally committed to the organization. Furthermore, maintaining long-term experienced employees with a proper status, instead of temporal employees, will lead to an emotional commitment to the organization and to attaining its achievements.
\end{abstract}

\section{Keywords:}

management style, decision-making, organizational commitment.

JEL Classification: D23, L20 